\title{
Monosomy 3
}

National Cancer Institute

\section{Source}

National Cancer Institute. Monosomy 3. NCI Thesaurus. Code C43305.

A chromosomal abnormality consisting of the absence of a copy (homolog) of chromosome 3. 